\title{
Clinical characteristics of intracranial hemorrhages in patients treated with direct oral anticoagulants in secondary stroke prevention
}

J. Martinez-Poles, A. De Felipe, S. García-Madrona, B. Escribano-Paredes, V. Nedkova Hristova, P. Pérez Torre, R. Álvarez Velasco, C. Matute, R. Vera, A. Cruz, J. Masjuan. Hospital Ramón y Cajal, Neurology, Madrid, Spain.

\section{Background and Aims}

Risk of hemorrhagic complications in patients anticoagulated after acardioembolic stroke is double than in primary prevention. Direct oral anticoagulants (DOACs) reduce the risk of intracranial hemorrhage (ICH) by $50 \%$ compared to warfarin. We present our clinical experience of $\mathrm{ICH}$ secondary to DOACs in secondary prevention.

\section{Method}

We performed an observational, retrospective study of anticoagulated patients with DOACs in secondary prevention of stroke from October 2010 to June 2015 at our center. Clinical, radiological and ICH variables were collected.

\section{Results}

We included 425 patients (women, 53.4\%; mean age $77.1 \pm 10.2$ yo). 40 patients were lost during follow-up. There were no differences in clinical variables (Table 1). DOAC distribution is detailed in Fig 1. Patients in treatment with Dabigatran has more prolonged follow-up due to its earlier commercialization (mean follow-up: Dabigatran 29.0 months; Rivaroxaban 25.0 months, Apixaban 15.5 months). Median CHA2DS2-VASc was 5 (range 2 - 8) and HAS-BLED was 2 (range 1 - 4).

\begin{tabular}{|l|c|c|c|}
\hline \multicolumn{4}{|c|}{ Table 1: Clinical variables } \\
\hline & $\begin{array}{c}\text { No ICH } \\
\text { N 375 }\end{array}$ & $\begin{array}{c}\text { ICH } \\
\text { N 10 }\end{array}$ & $p\left(\chi^{2}\right)$ \\
\hline Age & $77,1 \pm 10,2$ yo & $82,5 \pm 7,9$ yo & 0,62 \\
\hline Hypertension & $79 \%$ & $60 \%$ & 0,14 \\
\hline Diabetes & $26,1 \%$ & $30 \%$ & 0,78 \\
\hline Dyslipidemia & $43,9 \%$ & $40 \%$ & 0,79 \\
\hline Chronic kydney disease & $5 \%$ & $10 \%$ & 0,49 \\
\hline Previous ICH & $8,3 \%$ & $20 \%$ & 0,19 \\
\hline Myocardial infarction & $11,5 \%$ & $10 \%$ & 0,88 \\
\hline Peripheral arteriopathy & $5,7 \%$ & $10 \%$ & 0,57 \\
\hline
\end{tabular}

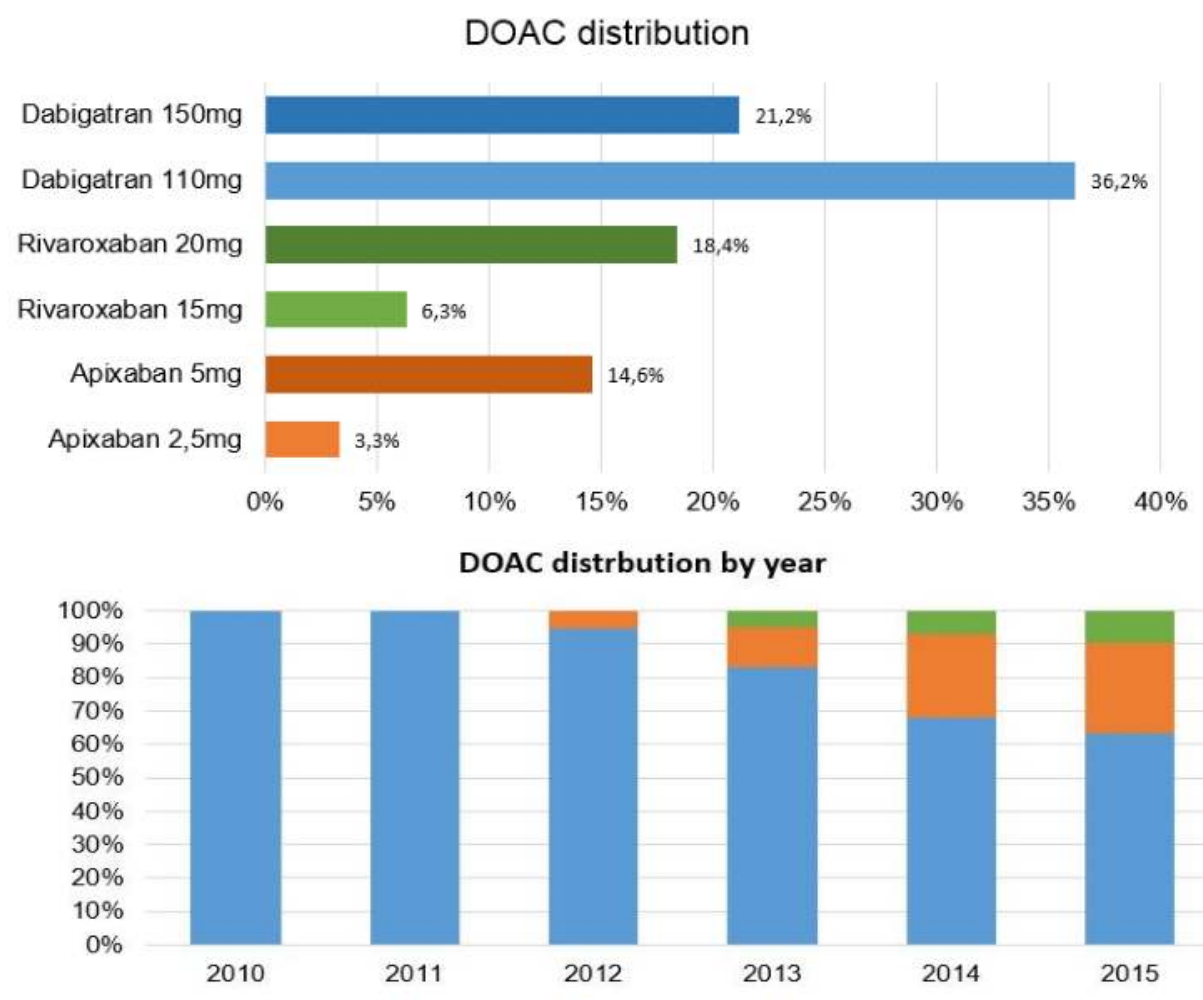

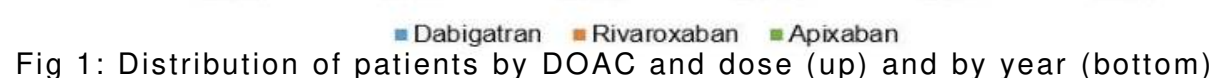

During follow-up there were $10 \mathrm{ICH}$ (0.015 cases/person-year), median of 36 months (7-

78) from the beginning of treatment. Patients were receiving treatment with Dabigatran (8), Apixaban (1) and Rivaroxaban (1).

There were 5 spontaneous intraparenchymal hematomas, 3 post-traumatic subarachnoid hemorrhage, an intraventricular hemorrhage and a subdural hematoma. Anticoagulation was reversed in 3 cases. Long-term secondary stroke prevention is shown in Table 2.
Table 2: Long-term secondary stroke prevention

\begin{tabular}{l|l}
$\begin{array}{l}\text { ACOD } \\
\text { discontinuation }\end{array}$ & $\begin{array}{l}4 \text { patients (intraparenchymal hemorrhages) } \\
1 \text { left atrial appendage closure }\end{array}$ \\
\hline $\begin{array}{l}\text { ACOD } \\
\text { continuation }\end{array}$ & $\begin{array}{l}4 \text { patients } \\
3 \text { post-traumatic SAH } \\
1 \text { post-traumatic subdural haematoma }\end{array}$
\end{tabular}

There were 2 deaths related to $\mathrm{ICH}$. At 3 months $70 \%$ presented $\mathrm{mRS} \leq 2$ (Figure 2).

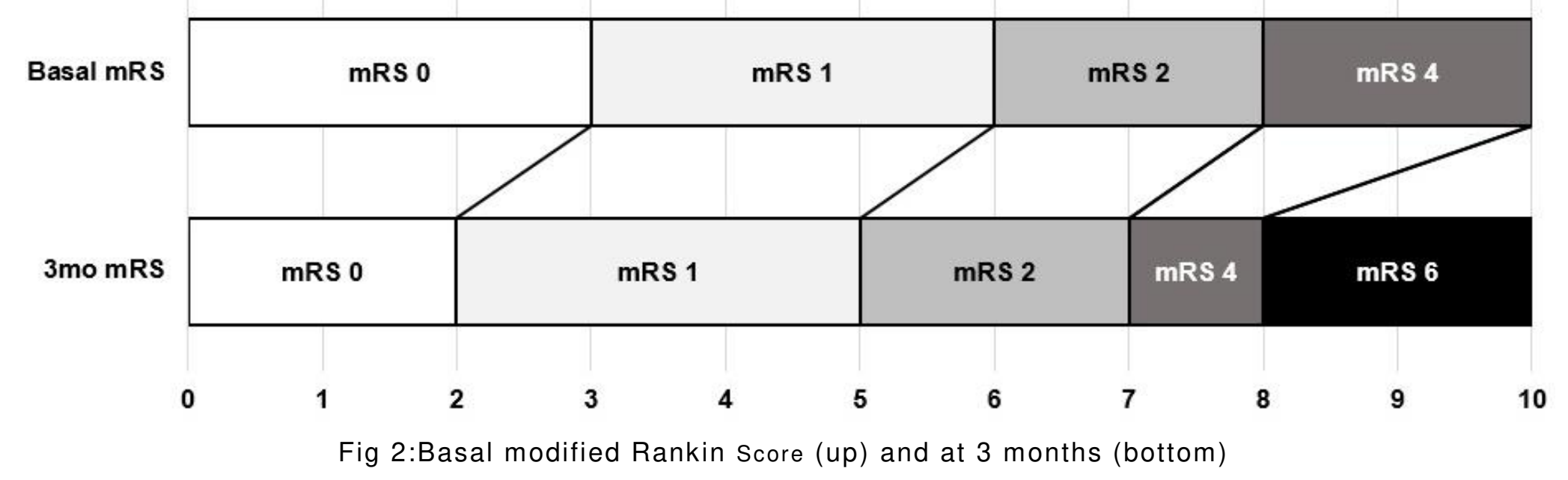

\section{Conclusions}

The rate of ICH in patients with DOACs in secondary stroke prevention was similar to that of the pivotal studies and patients presented low disability at 3 months.

\section{References}

1. Ruff CT, et al. Comparison of the efficacy and safety of new oral anticoagulants with warfarin in patients with atrial fibrillation: a meta-analysis of randomised trials. Lancet 2014;383(9921):955-62.

2. Wilson D, et al;. Outcome of intracerebral hemorrhage associated with different oral anticoagulants. Neurology 2017; 88:1693-1700.

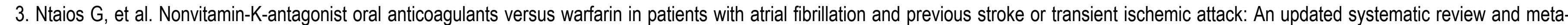
analysis of randomized controlled trials. Int J Stroke. 2017; 12: 589-596 